\title{
Th1 and Th2 Chemokines, Vaccine-Induced Immunity, and Allergic Disease in Infants After Maternal w-3 Fatty Acid Supplementation During Pregnancy and Lactation
}

\author{
CATRIN FURUHJELM, MARIA C. JENMALM, KARIN FÄLTH-MAGNUSSON, AND KAREL DUCHÉN
}

Department of Clinical and Experimental Medicine, Faculty of Health Sciences, Linköping University, 58185 Linköping, Sweden

\begin{abstract}
We investigated whether the previously reported preventive effect of maternal $\omega-3$ fatty acid supplementation on IgEassociated allergic disease in infancy may be mediated by facilitating a balanced circulating Th2/Th1 chemokine profile in the infant. Vaccine-induced immune responses at 2 y of age were also evaluated. Pregnant women, at risk of having an allergic infant, were randomized to daily supplementation with $1.6 \mathrm{~g}$ eicosapentaenoic acid and $1.1 \mathrm{~g}$ docosahexaenoic acid or placebo from the 25th gestational week through 3.5 mo of breastfeeding. Infant plasma was analyzed for chemokines (cord blood, 3, 12, 24 mo) and anti-tetanus and anti-diphtheria IgG (24 mo). High Th2-associated CCchemokine ligand 17 (CCL17) levels were associated with infant allergic disease $(p<0.05)$. In infants without, but not with, maternal history of allergy, the $\omega-3$ supplementation was related to lower CCL17/CXC-chemokine ligand 11 (CXCL11) (Th2/Th1) ratios $(p<$ $0.05)$. Furthermore, in nonallergic, but not in allergic infants, $\omega-3$ supplementation was linked with higher Th1-associated CXCL11 levels $(p<0.05)$, as well as increased IgG titers to diphtheria $(p=0.01)$ and tetanus ( $p=0.05$ ) toxins. Thus, the prospect of balancing the infant immune system toward a less Th2-dominated response, by maternal $\omega$-3 fatty acid supplementation, seems to be influenced by allergic status. (Pediatr Res 69: 259-264, 2011)
\end{abstract}

$\mathrm{C}$ hemokines are small chemotactic factors, produced by several cell types, macrophages being an important source (1). Some of them have a crucial role in maintaining the Th1/Th2 balance in immune responses against foreign proteins and these chemokines can be detected more easily than Th1/Th2 cytokines in peripheral blood (2). The chemokines CC-chemokine ligand 17 (CCL17) and CCL22 are induced by IL- 4 and IL- 13 and bind to the CCR4 receptor on Th2 cells (1). Increased levels of CCL17 and CCL22 have been associated with presence and severity of atopic derma-

Received June 29, 2010; accepted October 6, 2010.

Correspondence: Catrin Furuhjelm, M.D., Division of Pediatrics, Department of Clinical and Experimental Medicine, Faculty of Health Sciences, SE-581 85 Linköping., Sweden; e-mail: catrin.furuhjelm@telia.com

Supported by grants from Pharma Nord, Sadelmagervej 30-32, DK-7100 Vejle, Denmark; Medical Research Council of Southeast Sweden (FORSS); The Östergötland County Council; The Ekhaga Foundation; Swedish Asthma and Allergy Association; The Swedish Research Council for Environment; Agricultural Sciences and Spatial Planning (FORMAS); The Swedish Society of Medicine; The Swedish Medical Research Council; and Glaxo Smith Kline, Sweden.

This study is registered with ClinicalTrial.gov; clinical trial identifier: NCT00892684. titis in children and adults $(3,4)$. Furthermore, high CCL17 and CCL22 levels differentiate asthmatic children from nonatopic children with chronic coughing (5). On the other hand, the chemokines CXC-chemokine ligand 10 (CXCL10) and CXCL11 are induced by IFN $\gamma$, act chemotactically on Th1 skewed cells, and are associated with Th1-mediated conditions like Crohn's disease (6). Increased ratios of circulating CCL22/CXCL10, as a marker for Th2 like deviation, have been reported at birth in infants developing allergic disease during the first 2 y of life (2) and increased CCL22 levels in neonates have been associated to future wheezing (7). Although simplified, the Th1and Th2 model for immune responses is still valid with the additional consideration of $\mathrm{T}$ regulatory cells and Th17 cells (8). T-cell responsiveness to common food and inhalant allergens may occur already in the fetus (9). As Th2-skewed local immune responses have been suggested to be required for a successful pregnancy (10), the infant is born with an immune system predestined to Th2skewed responses to foreign antigens. Genetic predisposition to the development of early allergic disease seems to be related to sustained Th2-skewed immunity during infancy (11). We have previously found a decreased period prevalence of IgE-associated disease (i.e. eczema and food allergy, with concomitant allergic sensitization) up to $1 \mathrm{y}$ of age after maternal $\omega$-3 long chain polyunsaturated fatty acid (LCPUFA) supplementation during the last trimester of pregnancy and 3-4 mo of lactation (12). We also reported that low maternal arachidonic acid (AA, 20:4 $\omega$-6)/eicosapentaenoic acid (EPA, 20:5 $\omega-3)$ ratios were associated with decreased maternal secretion of AA-derived prostaglandin E2 (PGE2), a factor that is active in the allergic inflammation (13). The most probable explanation for this is that the $\omega-3$ LCPUFA EPA and the $\omega-6$ LCPUFA AA compete for the same enzymes, cylooxygenase and lipooxygenase, in their metabolism (14). The $\omega-3$ LCPUFAs EPA and docosahexaenoic acid (DHA, 22:6 $\omega$-3) are also vital structures of the cell membrane (15) and may generate inflammation resolving resolvins and docosatrienes $(16,17)$, thus exerting effects on antigen presenting cells, T-regulatory cells, epithelial cells (18), and monocytes (19). In addition, $\omega$-3 LCPUFAs

Abbreviations: AA, arachidonic acid $=20: 4 \omega-6$; CCL, CC-chemokine ligand; CXCL, CXC-chemokine ligand; DHA, docosahexaenoic acid = 22:6 $\omega-3$; dns, data not shown; EPA, eicosapentaenoic acid $=20: 5 \omega-3$; LCPUFA, long chain polyunsaturated fatty acids; PGE2, prostaglandin E2 
have effects on transcription factors that may alter gene expression in inflammatory cells (20). Through these mechanisms, the $\omega-3$ LCPUFAs might be able to accelerate the postnatal maturation of the Th2-deviated immune system, toward a more balanced immunity (21). Interestingly, the preventive effect of $\omega-3$ supplementation on the development of allergy in infants and decreasing PGE2 synthesis in mothers during the last trimester of pregnancy were both more pronounced if the mother was not allergic $(12,13)$. This is in line with previous studies reporting different biological effects of dietary $\omega$-3 LCPUFA in different individuals or populations (22).

Allergic children have been shown to be intrinsically hyporesponsive to vaccines, possibly because of Th2-skewed immune responses, even though this seems to be overcome by common vaccination regimens (23). Omega-3 fatty acids have been shown to enhance the Th1 responses through IL-2 and IFN $\gamma$ production (18) and may therefore affect vaccine antibody responses.

We thus hypothesize that the prophylactic effect of maternal $\omega-3$ fatty acid supplementation in pregnancy and lactation on the development of allergic disease in infancy is mediated by facilitating a balanced Th2/Th1 circulating chemokine profile in the infant predisposed to develop IgE-associated disease, particularly if the mother is nonallergic. We also hypothesize that the $\omega$-3 fatty acids may enhance the immunological response to vaccines in allergic and nonallergic infants.

We aimed to measure the circulating Th2-associated chemokines CCL17 and CCL22 and Th1-associated chemokines CXCL10 and CXCL11 in infant plasma throughout the first $2 \mathrm{y}$ of life and relate them to $\omega-3$ fatty acid supplementation and the development of eczema and IgE-associated allergic disease, both in the whole study group and in the infants of mothers with and without allergic symptoms separately. The secondary aim was to measure $\operatorname{IgG}$ antibody responses to tetanus and diphtheria vaccines and relate them to maternal $\omega-3$ fatty acid supplementation in infants of mothers with and without a history of allergic symptoms, as well as in allergic and nonallergic infants.

\section{METHODS}

Study design and subjects. This study was part of a prospective, doubleblind, placebo-controlled trial in Sweden including 99 families from Linköping and 46 families from Jönköping. At least one family member had a history of allergic disease. The mothers started the intake of capsules containing the $\omega-3$ LCPUFAs, EPA $(1.6 \mathrm{~g} / \mathrm{d})$ and DHA $(1.1 \mathrm{~g} / \mathrm{d})$, or placebo produced by Pharma Nord, Vejle, Denmark, in the 25th wk of gestation and continued through the first 3-4 mo of breastfeeding. Twenty-five mothers did not complete at least $15 \mathrm{wk}$ of supplementation and they were excluded (12).

The infants were followed up at $3,6,12$, and 24 mo of age with clinical examinations, allergy testing, and questionnaires regarding symptoms of allergic disease. Plasma samples for phospholipids fatty acid proportions and immunological analyses were collected at birth, 3, 12, and 24 mo. All the analyses were performed at the laboratory of Clinical and Experimental Medicine at the University Hospital of Linköping. When studying the groups of subjects with available data at each time point separately, the two intervention groups did not differ regarding potential confounders, such as sex, birth order, cesarean sections, family history of allergic disease, maternal $\omega-3$ fatty acid levels before study entry, breastfeeding at 3 and 6 mo, exposure to tobacco smoke and/or furry pets up to 24 mo of age, or daycare attendance. The number infants whose mothers had allergic symptoms and the infant cumulative incidence of IgE-associated disease are presented in Table 1 for each intervention group.

The variation in availability of data was due to the fact that chemokines were analyzed in plasma samples from Linköping only, whereas vaccineinduced responses were analyzed in plasma/serum samples from both Linköping and Jönköping. All infants included in the analysis of vaccine-induced immunity at $2 \mathrm{y}$ of age received one dose of Pentavac or Infanrix containing tetanus toxoid ( $\geq 30 \mathrm{IU}$ ) and diphtheria toxoid ( $\geq 40 \mathrm{IU}$ ) at ages 3,5 , and 12 mo according to the Swedish vaccination program.

Clinical definitions. Food reaction: gastrointestinal symptoms, hives, aggravated eczema, or wheezing after ingestion of a certain food with recovery after food elimination and reoccurrence of symptoms after ingestion of the particular food. Eczema: reoccurring and itching eczematous, lichenified, or nummular dermatitis (24). Asthma: doctor diagnosed wheezing at least three times during the first $2 \mathrm{y}$. Rhinoconjunctivitis: itching and running eyes and nose in the spring. A child with eczema, food reaction, asthma, or rhinoconjunctivitis was diagnosed with allergic symptoms. Concomitant sensitization, i.e. positive skin prick test (SPT) and/or detectable circulating specific $\operatorname{IgE}$ antibodies, defined IgE-associated disease.

Table 1. Number of infants with available chemokine data $(A)$ and data on vaccine-induced responses $(B)$ in the subgroups of infants with and without maternal history of allergic disease and with or without $\operatorname{IgE}$ associated disease up to 2 years of age

\begin{tabular}{|c|c|c|c|c|c|c|c|c|c|c|c|c|}
\hline & \multicolumn{3}{|c|}{ Cord Blood } & \multicolumn{3}{|c|}{$3 \mathrm{mo}$} & \multicolumn{3}{|c|}{$12 \mathrm{mo}$} & \multicolumn{3}{|c|}{$24 \mathrm{mo}$} \\
\hline & $\begin{array}{c}\omega-3 \\
\mathrm{n}(\%)\end{array}$ & $\begin{array}{l}\text { Placebo } \\
\text { n }(\%)\end{array}$ & $p \dagger$ & $\begin{array}{c}\omega-3 \\
\mathrm{n}(\%)\end{array}$ & $\begin{array}{l}\text { Placebo } \\
\mathrm{n}(\%)\end{array}$ & $p^{\dagger}$ & $\begin{array}{c}\omega-3 \\
\mathrm{n}(\%)\end{array}$ & $\begin{array}{c}\text { Placebo } \\
\mathrm{n}(\%)\end{array}$ & $p \dagger$ & $\begin{array}{c}\omega-3 \\
\mathrm{n}(\%)\end{array}$ & $\begin{array}{l}\text { Placebo } \\
\mathrm{n}(\%)\end{array}$ & $p \dagger$ \\
\hline \multicolumn{13}{|l|}{ A } \\
\hline Infants of allergic mothers $\ddagger$ & $23 / 32(72)$ & $27 / 40(68)$ & NS & $15 / 22(68)$ & $12 / 20(60)$ & NS & $21 / 30(70)$ & $22 / 31(71)$ & NS & $23 / 31(74)$ & $18 / 30(60)$ & NS \\
\hline Infants of nonallergic mothers* & $9 / 32(28)$ & $13 / 40(32)$ & & $7 / 22(32)$ & $8 / 20(40)$ & & $9 / 30(30)$ & 9/31 (29) & & $8 / 31(26)$ & $12 / 30(40)$ & \\
\hline $\begin{array}{l}\text { Infants with IgE associated } \\
\text { disease } \S\end{array}$ & $5 / 18(28)$ & $13 / 30(43)$ & NS & $3 / 12(25)$ & $9 / 16(56)$ & NS & $5 / 18(28)$ & $10 / 29(34)$ & NS & $6 / 20(30)$ & $11 / 24(46)$ & NS \\
\hline Nonallergic infants $\|$ & $13 / 18(72)$ & $17 / 30(57)$ & & $9 / 12(75)$ & $7 / 16(44)$ & & $13 / 18(72)$ & $19 / 29(65)$ & & $14 / 20(70)$ & $13 / 24(54)$ & \\
\hline \multicolumn{13}{|l|}{ B } \\
\hline Infants of allergic mothers $\ddagger$ & & & & & & & & & & $31 / 45(67)$ & $29 / 49(59)$ & NS \\
\hline Infants of nonallergic mothers* & & & & & & & & & & $14 / 45(31)$ & $20 / 49(41)$ & \\
\hline $\begin{array}{l}\text { Infants with } \operatorname{IgE} \text { associated } \\
\text { disease } \S\end{array}$ & & & & & & & & & & $5 / 27(18)$ & $17 / 37(46)$ & $<0.05$ \\
\hline Nonallergic infants $\|$ & & & & & & & & & & $22 / 27(82)$ & $20 / 37(54)$ & \\
\hline
\end{tabular}

* Mothers with no history of allergic symptoms.

$\dagger \chi^{2}$ test.

\$ Mothers with a history of allergic symptoms.

$\S$ Children with asthma, eczema, food reactions, or rhinoconjunctivitis and sensitization.

\| Children with no allergic symptoms or sensitisation. Some children were not categorized because of sensitization without symptoms or vice versa. NS, not significant. 
Sensitization. SPTs were performed on the infants at 6,12, and 24 mo with milk, egg, wheat, and cat extract. At $24 \mathrm{mo}$, timothy-grass and birch allergen extracts were added (ALK-ABELLÓ, Hørsholm, Denmark; Soluprick). A wheal diameter $\geq 3 \mathrm{~mm}$ was considered positive. Specific $\mathrm{IgE}$ antibodies toward egg, milk, wheat, and cat were analyzed in serum samples from the infants at 12 and $24 \mathrm{mo}$. At $24 \mathrm{mo}$, timothy-grass and birch were added to the analysis. The detection limit was $0.35 \mathrm{kU} / \mathrm{L}$.

Fatty acid analysis. Analysis of phospholipids was performed separating lipid fractions on a SEP-PAK aminopropyl cartridge (Waters Sverige AB, Sollentuna, Sweden) according to a method originally described by Kaluzny et al. (25). Samples were transmethylated in methanolic-HCl-3N (VWR) at $80^{\circ} \mathrm{C}$ for $4 \mathrm{~h}$. The fatty acid methyl esters were separated by Agilent Technologies 6890N Network GC System gas chromatograph (Agilent Technologies, Stockholm, Sweden). C21:0 methyl ester (Larodan, Malmö, Sweden) was added as an internal standard, and the fatty acid methyl esters were identified by comparing the retention times of the peaks with those of a known standard (Mixture Me 100; Larodan Fine Chemicals AB, Malmö, Sweden). The levels were expressed as mol\% (13).

Chemokine analyses in venous blood. Venous blood was collected from the umbilical cord and at 3,12 , and 24 mo. It was stored in $-70^{\circ} \mathrm{C}$ as heparinized plasma until assessment. The chemokines CXCL10/IP10, CXCL11/I-TAC, CCL17/TARC, and CCL22/MDC were analyzed with an in-house multiplexed Luminex assay. Before commencing the multiplexed assay, monoclonal capture antibodies were covalently coupled to carboxylated microspheres (Luminex Corporation, Austin, TX). Five micrograms antibody per $10^{6}$ microspheres of monoclonal anti-human CXCL10 (clone 4D5; BD Biosciences, Stockholm, Sweden), CXCL11 (clone 87328), CCL17 (clone 54026), and CCL22 (clone 57226; R\&D Systems, Minneapolis, MN) antibodies were used. Two thousand coupled microspheres of each number dissolved in $50 \mu \mathrm{L}$ PBS (Medicago AB) with 1\% BSA (Sigma Chemical Co.-Aldrich, Stockholm, Sweden) were added to each well of a $1.2-\mu \mathrm{m}$ pore-size filter plate (Millipore multiscreen; Millipore Corporation, Bedford, MA). Recombinant human CXCL10, CXCL11, CCL17, and CCL22 (R\&D Systems) were used as standards. Fifty microliters blank and diluted samples (final dilution 1:2) were also added to the microspheres and incubated over night at $4{ }^{\circ} \mathrm{C}$. After two washes, the microspheres were resuspended in $100-\mu \mathrm{L}$ biotinylated anti-human CXCL10 (1000 ng/mL; BD Biosciences, Stockholm, Sweden), CXCL11 (500 ng/mL BAF320), CCL17 (500 ng/mL, BAF364), and CCL22 (200 ng/mL, BAF336) antibody (R\&D Systems) solution. After 1-h incubation, the microspheres were washed twice, resuspended, and incubated in $100 \mu \mathrm{L}$ of $1 \mu \mathrm{g} / \mathrm{mL}$ Streptavidin R-phycoerythrin conjugate (Molecular Probes, Eugene, OR) for $30 \mathrm{~min}$. After two washes, the samples were analyzed on a Luminex (100) instrument (Biosource, Nivelles, Belgium) and the data were acquired using the StarStation 2.3 software (Applied cytometry systems, Sheffield, UK). The limit of detection was $6 \mathrm{pg} / \mathrm{mL}$ for CXCL10, 14 $\mathrm{pg} / \mathrm{mL}$ for CXCL11, $2 \mathrm{pg} / \mathrm{mL}$ for CCL17, and $2 \mathrm{pg} / \mathrm{mL}$ for CCL22. All samples were analyzed in duplicates, and the sample was reanalyzed if the coefficient of variance $(\mathrm{CV})$ was $>15 \%$.

Measurements of vaccine specific antibody concentrations. Venous blood was collected at $24 \mathrm{mo}$ and stored in $-70^{\circ} \mathrm{C}$ as heparinized plasma or serum until assessment. High-binding ELISA plates (Costar 3590; Life Technologies, Täby, Sweden) were coated with $100 \mu \mathrm{L} /$ well of $1 \mathrm{Lf} / \mathrm{mL}$ tetanus toxoid or $1 \mathrm{Lf} / \mathrm{mL}$ diphtheria toxoid (Statens Serum Institute, Copenhagen, Denmark) and diluted in PBS. The plates were incubated overnight at room temperature and then blocked for $60 \mathrm{~min}$ in room temperature using 100 $\mu \mathrm{L} /$ well of $0.5 \%$ BSA in PBS. After washing with PBS-Tween, a standard curve was added (WHO international standard TE-3, $120 \mathrm{IU} / \mathrm{mL}$ or Diphteria antitoxin Human 00/496, both from the National Institute for Biological Standard and Control, Hertfordshire, UK) and diluted in PBS-Tween in seven steps. Hundred microliters per well in duplicates was added of standard and samples and incubated for $1 \mathrm{~h}$ in room temperature. Serum IgG42 (Swedish Institute for Infectious Disease Control) was used as a control and diluted 1:3000. After washing, $100 \mu \mathrm{L} /$ well of alkaline phosphatase conjugated mouse anti-human IgG antibodies (clone A-1543; Sigma Chemical Co.Aldrich) diluted in 1:5000 in PBS was added and incubated for $1 \mathrm{~h}$. Two hundred microliters per well of FAST-pNPP substrate (Sigma Chemical Co.-Aldrich) was added. After $30 \mathrm{~min}$, the reaction was terminated by $100 \mu \mathrm{L}$ $\mathrm{NaOH}$. The optical densities were read at $405 \mathrm{~nm}$ in a VersaMax tunable microplate reader (Molecular Devices, Sunnyvale, CA). The limits of detection were $16 \mathrm{mIU} / \mathrm{mL}$ for diphtheria and $78 \mathrm{mIU} / \mathrm{mL}$ for tetanus.

Statistics. The $t$ test and the $\chi^{2}$ test were used for comparison of potential confounders between the placebo- and $\omega-3$ supplemented groups. The MannWhitney $U$ test was used to compare levels of nonparametric parameters (chemokines, anti-tetanus, and anti-diphtheria antibodies) between groups. Spearman's correlation was used for correlation of nonparametric variables. Friedman's test was used for analysis of repeated measures of CCL17. A $p$-value $<0.05$ was considered statistically significant. Statistical analyses were performed using SPSS software 15.0 for Windows (SPSS Inc, Chicago, IL).

Ethics. An informed consent was obtained from both parents before inclusion. The Regional Ethics Committee for Human Research at Linköping University approved the study.

\section{RESULTS}

Chemokines. Infants with IgE-associated disease, during the first $2 \mathrm{y}$, had higher CCL17 concentrations at 12 mo than infants without allergic symptoms or sensitization. From birth to $3 \mathrm{mo}$, the CCL17 levels declined significantly in the nonallergic group, whereas it seemed to be unchanged in the allergic group during the first year of life (Fig. 1A). At 3 and 12 mo of age, the CCL17 levels were significantly higher in the group of infants with eczema regardless of sensitization during the first 2 y compared with infants without eczema (Fig. 1B). At $3 \mathrm{mo}$, the CCL17/CXCL11 ratio was also higher in the infants with eczema than without $[0.22(0.06-0.80)$ versus $0.14(0.03-0.40) ; p<0.05]$. There were no significant differences in CCL17 levels or CCL17/CXCL11 ratios between infants with food reactions $(n=17)$ or asthma $(n=10)$ regardless of sensitization and infants without allergic symptoms, data not shown (dns). No differences were detected in the levels of CXCL10, CXCL11, and CCL22 between nonallergic and allergic infants at any time point (dns).

Throughout the follow-up, the CXCL10, CXCL11, CCL17, or CCL22 levels were similar in the $\omega-3$ group and the placebo

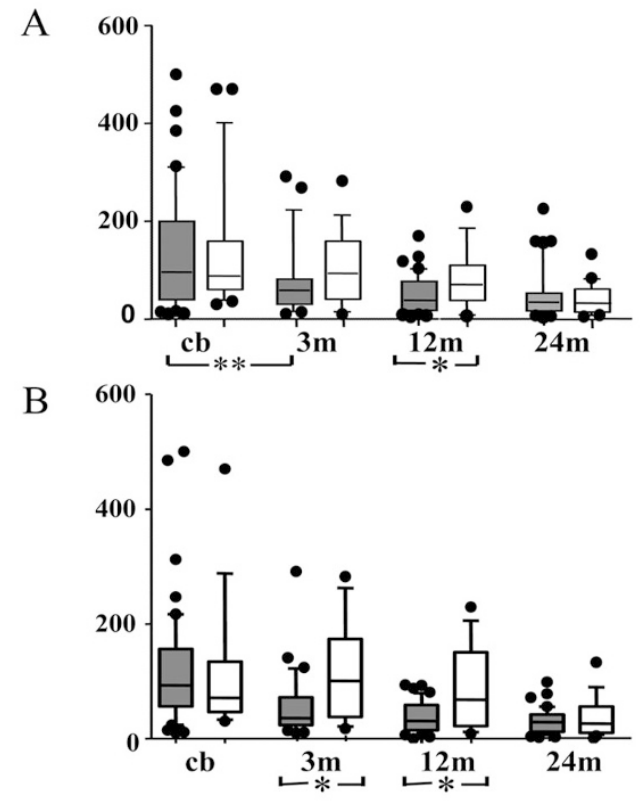

Figure 1. Circulating CCL17 levels during infancy in relation to allergic disease. (A) CCL17 levels in infants with IgE-associated disease (white bars, $n=18,12,15$, and 17) and infants without allergic symptoms (eczema, food reaction, asthma, or rhinoconjunctivitis) or sensitization (gray bars, $n=30$, 16, 32, and 27). Between cord blood and 3 mo, the CCL17 levels decreased in the nonallergic group. At $12 \mathrm{mo}$, the nonallergic group had lower levels of CCL17 compared with the infants with IgE-associated disease, $* p<0.05$, Mann-Whitney $U$ test; **p $<0.01$, Friedman's test. (B) CCL17 levels in infants with eczema regardless of sensitization (white bars, $n=17,11,14$, and 16) and infants without eczema (gray bars, $n=54,30,46$, and 45) At 3 and $12 \mathrm{mo}$, the infants with eczema had higher CCL17 levels compared with the infants without eczema, $* p<0.05$, Mann-Whitney $U$ test. Bars show median, 10th and 90th percentiles. 
Table 2. Chemokine levels and vaccine-induced IgG titers in the infants whose mothers were randomized to $\omega$-3 supplementation or placebo from gestational wk 25 until 3.5 mo after delivery

\begin{tabular}{|c|c|c|c|c|c|c|c|c|c|c|}
\hline & \multicolumn{5}{|c|}{ Cord blood } & \multicolumn{5}{|c|}{$3 \mathrm{mo}$} \\
\hline & \multicolumn{2}{|c|}{$\omega-3$} & \multicolumn{2}{|c|}{ Placebo } & \multirow[b]{2}{*}{$p^{*}$} & \multicolumn{2}{|c|}{$\omega-3$} & \multicolumn{2}{|c|}{ Placebo } & \multirow[b]{2}{*}{$p^{*}$} \\
\hline & Median & Range & Median & Range & & Median & Range & Median & Range & \\
\hline $\begin{array}{l}\text { CXCL10 } \\
\text { (pg/mL) }\end{array}$ & 21 & $11-78$ & 21 & $9-79$ & NS & 63 & $32-127$ & 46 & $24-256$ & NS \\
\hline $\begin{array}{l}\text { CXCL11 } \\
\text { (pg/mL) }\end{array}$ & 387 & $17-770$ & 294 & $28-901$ & NS & 242 & $13-60$ & 218 & $93-1068$ & NS \\
\hline $\begin{array}{l}\text { CCL22 } \\
\text { (pg/mL) }\end{array}$ & 131 & $11-282$ & 122 & $7-573$ & NS & 288 & $139-596$ & 327 & $118-724$ & NS \\
\hline $\begin{array}{l}\text { CCL17 } \\
\text { (pg/mL) }\end{array}$ & 99 & $17-500$ & 87 & $11-485$ & NS & 37 & $11-292$ & 57 & $10-183$ & NS \\
\hline \multicolumn{11}{|l|}{ Anti-tetanus } \\
\hline \multicolumn{11}{|l|}{ Anti-diphteria } \\
\hline $\mathrm{IgG}(\mathrm{mIU} / \mathrm{L})$ & & & & & & & & & & \\
\hline
\end{tabular}

group (Table 2). Maternal EPA and DHA proportions 1 wk after delivery correlated to CXCL11 levels in the infant at 12 mo ( $\rho=0.28$ and $\rho=0.3 ; p<0.05$ for both). However, no other correlations were found between the chemokines and maternal fatty acid status.

In the group of infants whose mothers did not have a history of allergic symptoms (see Table 1 for $n$ ), infants with eczema or food reactions, regardless of sensitization, had higher CCL17 levels and CCL17/CXCL11 ratios at 12 mo compared with infants without eczema or food reactions during the first 2 y [CCL17: 77 (54-229) $\mathrm{pg} / \mathrm{mL}$ versus 28 (7-79) $\mathrm{pg} / \mathrm{mL}$ and CCL17/CXCL11: $0.2(0.1-1.0) \mathrm{pg} / \mathrm{mL}$ versus $0.1(0.03-0.25)$ $\mathrm{pg} / \mathrm{mL} ; p<0.01$ for both]. Moreover, maternal $\omega-3$ fatty acid supplementation was associated with lower levels of CCL17 at $12 \mathrm{mo}$ [ $\omega-3: 27(7-78) \mathrm{pg} / \mathrm{mL}$ versus placebo: $71(18-230)$ $\mathrm{pg} / \mathrm{mL} ; p<0.05]$ and lower ratios of CCL17/CXCL11 at 3 and 12 mo (Fig. 2) in the group of infants without, but not with, maternal heredity of allergy. Accordingly, the ratio of CCL17/CXCL11 at 12 mo correlated inversely to maternal EPA and DHA status $1 \mathrm{wk}$ after delivery in the infants without, but not with, maternal history of allergy (Fig. 3).

Within the group of infants without allergic symptoms or sensitization, the CXCL11 levels were higher in the $\omega-3$ supplemented group than in the placebo group at birth and at 12 mo [386 (141-770) $\mathrm{pg} / \mathrm{mL}$ versus 240 (28-652) pg/mL and 331 (133728) $\mathrm{pg} / \mathrm{mL}$ versus 274 (146-599) $\mathrm{pg} / \mathrm{mL} ; p<0.05$ for both], a difference that was not seen in the group of allergic infants.

Vaccine-induced immune responses. Anti-tetanus and antidiphtheria IgG levels were similar in the infants with and without allergic disease (dns) and also in the placebo and the $\omega$-3 groups (Table 2) regardless of maternal allergic history (dns). In the group of infants without allergic symptoms or sensitization, the levels of anti-diphtheria IgG were higher in the $\omega-3$ supplemented group compared with the placebo group, and there was also a trend toward higher levels of anti-tetanus IgG (Fig. 4). There were no such findings in the group of allergic infants.

\section{DISCUSSION}

Development of allergic disease in infancy has been related to prolonged Th2-skewed immune responses toward foreign antigens (11). Now we report an association between IgEassociated disease as well as symptoms of eczema during the first $2 \mathrm{y}$ and increased levels of the Th2 chemokine CCL17 and CCL17/CXCL11 ratios, supporting earlier findings of an altered Th2/Th1 immunological balance in the allergic child (2). CCL17 has been associated with allergic disease in several studies (3-5) but so has CCL22 $(2,4)$, an association that was not found in this study.

Maternal $\omega$-3 LCPUFA supplementation supposedly influences the infant immune system toward a balanced Th2/Th1 immune response to prevent allergic disease. Dunstan et al. (26) found a consistent trend for attenuated infant Th1 (IFN $\gamma$ ), Th2 (IL-5, IL-13) as well as IL-10 responses to allergens after $\omega$-3 supplementation of 89 atopic mothers during pregnancy. However, the neonates, whose mothers received fish oil, had significantly lower levels of circulating IL-13 in cord blood compared with the control group, which may reflect a subtle cytokine-shift favoring Th1 immunity (27). On the other hand, we did not see any effect of maternal $\omega$-3 LCPUFA supplementation on chemokines when analyzing all infants, although high EPA and DHA concentrations very early in life were associated with high levels of the Th1 chemokine CXCL11 in the infant. Nevertheless, in infants of nonallergic mothers, $\omega-3$ supplementation was associated with reduced levels of the Th2-related chemokine CCL17.

Maternal $\omega-3$ supplementation was not related to either higher IgG antibody levels against tetanus or diphtheria in all infants. However, when analyzing nonallergic infants, we found enhanced vaccine-induced immunity in the $\omega$-3 supplemented group compared with the placebo group, suggesting Th1 enhancing properties of $\omega-3$ LCPUFA in this particular group. One study in adults with six participants has indicated that the humoral response from B-cells, including the response 
Table 2. (Continued)

\begin{tabular}{|c|c|c|c|c|c|c|c|c|c|c|}
\hline & \multicolumn{5}{|c|}{$12 \mathrm{mo}$} & \multicolumn{5}{|c|}{$24 \mathrm{mo}$} \\
\hline & \multicolumn{2}{|c|}{$\omega-3$} & \multicolumn{2}{|c|}{ Placebo } & \multirow[b]{2}{*}{$p^{*}$} & \multicolumn{2}{|c|}{$\omega-3$} & \multicolumn{2}{|c|}{ Placebo } & \multirow[b]{2}{*}{$p^{*}$} \\
\hline & Median & Range & Median & Range & & Median & Range & Median & Range & \\
\hline $\begin{array}{l}\text { CXCL10 } \\
(\mathrm{pg} / \mathrm{mL})\end{array}$ & 59 & $26-325$ & 73 & $17-217$ & NS & 57 & $30-217$ & 60 & $4-72$ & NS \\
\hline $\begin{array}{l}\text { CXCL11 } \\
\quad(\mathrm{pg} / \mathrm{mL})\end{array}$ & 289 & $134-1110$ & 320 & $6-600$ & NS & 296 & $146-914$ & 254 & $25-207$ & NS \\
\hline $\begin{array}{l}\mathrm{CCL} 22 \\
\quad(\mathrm{pg} / \mathrm{mL})\end{array}$ & 207 & $14-376$ & 183 & $34-576$ & NS & 168 & $42-343$ & 149 & $130-948$ & NS \\
\hline $\begin{array}{l}\text { CCL17 } \\
\quad(\mathrm{pg} / \mathrm{mL})\end{array}$ & 31 & $1-181$ & 43 & $7-230$ & NS & 30 & $3-133$ & 25 & $22-382$ & NS \\
\hline $\begin{array}{l}\text { Anti-tetanus } \\
\qquad \operatorname{IgG}(\mathrm{mIU} / \mathrm{L})\end{array}$ & & & & & & 1024 & $285-6215$ & 910 & $106-7071$ & NS \\
\hline $\begin{array}{l}\text { Anti-diphteria } \\
\text { IgG (mIU/L) }\end{array}$ & & & & & & 262 & $8-2335$ & 191 & $8-2066$ & 0.066 \\
\hline
\end{tabular}

*Mann-Whitney $U$ test.

NS, not significant.

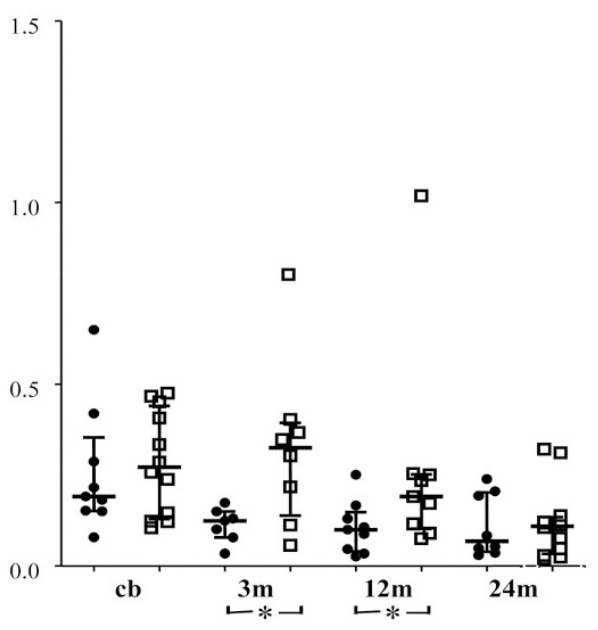

Figure 2. CCL17/CXCL11 in infants whose mothers did not have a history of allergic symptoms. At 3 and 12 mo, the $\omega$-3 group (@) had lower CCL17/CXCL11 ratios compared with the placebo group $(\square),{ }^{*} p<0.05$, Mann-Whitney $U$ test. Bars show median, 10th and 90th percentiles.
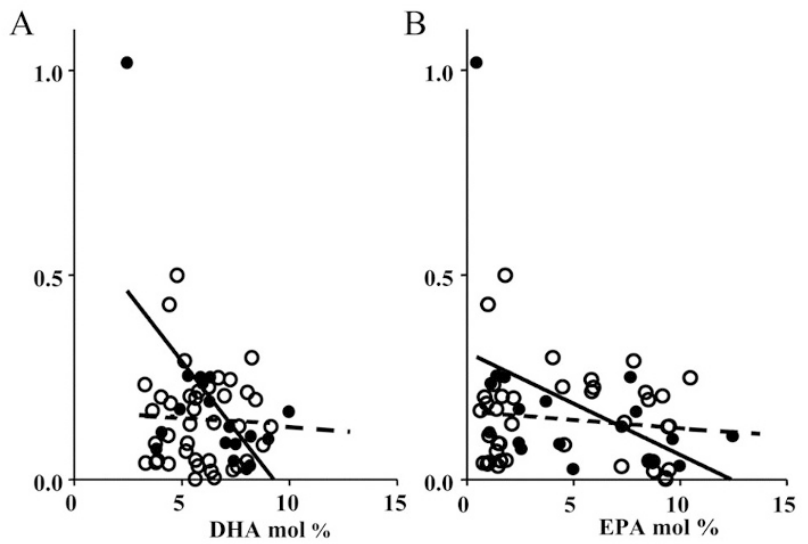

Figure 3. Correlations between the CCL17/CXCL11 ratios at $12 \mathrm{mo}$ in the infants and maternal DHA $(A)$ and EPA $(B)$ proportions 1 wk after delivery. -, no maternal history of allergic symptoms. $A$ : $\rho=-0.507, p<0.05 ; B$ : $\rho=$ $-0.546, p<0.05$, Spearman correlation. $\bigcirc$, maternal history of allergic symptoms (NS correlations for A and B).
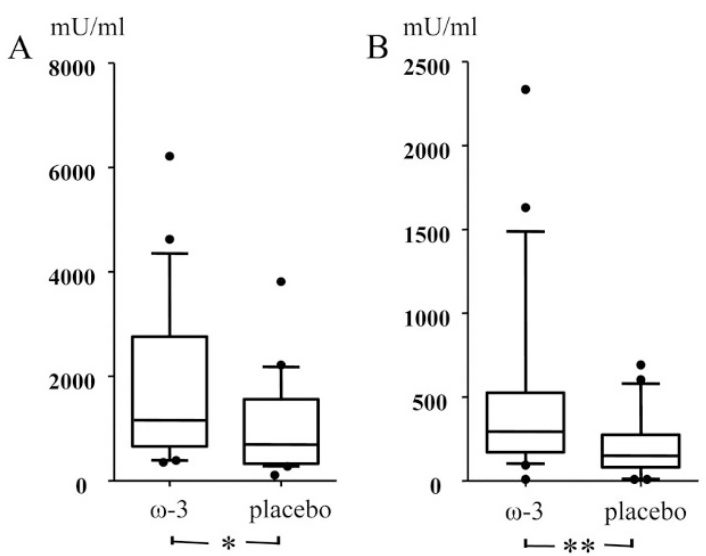

Figure 4. Vaccine-induced responses in nonallergic infants at $24 \mathrm{mo}$ of age. Bars show median, 10th and 90th percentiles. The infants in the $\omega-3$ group $(n=22)$ had higher anti-tetanus $(A)$ and anti-diphtheria $(B)$ titers compared with the placebo group $(n=20) *{ }^{*} p=0.05, * * p=0.01$, Mann-Whitney $U$ test.

to tetanus toxoid booster, is depressed after consumption of fish oil, 2.7-6 g daily for $6 \mathrm{wk}$ (28). Given the small sample size and that the study was performed in adults, those results might not be valid in our setting. Our results may corroborate the hypothesis that the $\omega$-3 fatty acids skew the immune system toward more balanced Th2/Th1 responses (18) and thereby strengthen the antimicrobial response. In line with this, Prescott et al. (29) found an association between increased $\mathrm{Th} 2$ response, i.e. serum $\mathrm{IgE}$, and reduced responsiveness to DPT vaccination during infancy.

In the group of infants whose mothers had no history of allergic disease, low CCL17/CXCL11 ratios were associated both with $\omega-3$ fatty acid supplementation and decreased incidence of eczema or food reactions during the first year of life. This is consistent with the more pronounced effect in nonallergic than allergic mothers of $\omega$-3 supplementation on the prevention of allergy in the infants (12) and decreasing maternal PGE2 synthesis in pregnancy (13). Previously, atopy has been associated with a disturbed fatty acid metabolism in maternal blood (30) and low $\omega-3$ LCPUFA in mature breast 
milk (31). This is supported by reports that atopy has been linked to the same region in chromosome 11 as the genes FADS1 and FADS2, coding for the rate limiting LCPUFA desaturases Delta-5 desaturase and Delta-6 desaturase $(32,33)$ and influencing breast milk essential fatty acid composition and plasma phospholipid content during pregnancy (34).

In this study, there were also increased vaccine-induced responses and levels of the Th1 chemokine CXCL11 in the $\omega-3$ supplemented group compared with the placebo group within the nonallergic but not within the allergic infants. Hence, it seems that the allergic predisposition of both the infant and the mother modifies the effect of the $\omega$-3 supplementation in the infant.

To our knowledge, this is the first study assessing circulating infant Th1 and Th2 chemokines after $\omega$-3 fatty acid supplementation during pregnancy and lactation in relation to allergic disease. The study was not originally designed to investigate the effects in the offspring of allergic and nonallergic mothers separately. Nevertheless, the statistically significant associations between $\omega-3$ supplementation and a less Th2-dominated immune response were found in infants whose mothers had no history of allergic disease. Interestingly, in the group of nonallergic infants, more pronounced responses to vaccines were seen after $\omega$-3 supplementation compared with placebo, which may also indicate a strengthened Th1 response. Our results may encourage future research, designed to explore this gene-by-environment interaction further and including genetic analyses.

Acknowledgments. We thank all the participating families; excellent research nurses Lena Lindell, Kicki Helander and Linnea Andersson; and Anne-Marie Fornander and Martina Abelius for laboratory work. Our sincere thanks to Malin Fagerås, who initially launched the idea of analysing chemokines in this project and Kristina Warstedt, who organized the laboratory work and analysed fatty acids. We are grateful to Johanna Larsson for clinical examinations of the infants in Jönköping. Professor Birgitta Strandvik and Mrs. Berit Holmberg, Department of Pediatrics, Institute of the Health of Women and Children, Gothenburg University kindly shared their expertise regarding the LCPUFA phospholipids analysis technique. We specially thank Benjamin Kersley for language advice.

\section{REFERENCES}

1. Pease JE, Williams TJ 2006 Chemokines and their receptors in allergic disease. J Allergy Clin Immunol 118:305-318

2. Sandberg M, Frykman A, Ernerudh J, Berg G, Matthiesen L, Ekerfelt C, Nilsson LJ, Jenmalm MC 2009 Cord blood cytokines and chemokines and development of allergic disease. Pediatr Allergy Immunol 20:519-527

3. Narbutt J, Lesiak A, Sysa-Jedrzeiowska A, Zakrzewski M, Bogaczewicz J, Stelmach I, Kuna P 2009 The imbalance in serum concentration of Th-1- and Th-2-derived chemokines as one of the factors involved in pathogenesis of atopic dermatitis. Mediators Inflamm 2009:269541

4. Shimada Y, Takehara K, Sato S 2004 Both Th2 and Th1 chemokines (TARC/ CCL17, MDC/CCL22, and MIG/CXCL9) are elevated in sera from patients with atopic dermatitis. J Dermatol Sci 34:201-208

5. Hartl D, Griese M, Nicolai T, Zissel G, Prell C, Konstantopoulos N, Gruber R, Reinhardt D, Schendel DJ, Krauss-Etschmann S 2005 Pulmonary chemokines and their receptors differentiate children with asthma and chronic cough. J Allergy Clin Immunol 115:728-736
6. Singh UP, Singh S, Iqbal N, Weaver CT, McGhee JR, Lillard JW Jr 2003 IFN-gamma-inducible chemokines enhance adaptive immunity and colitis. J Interferon Cytokine Res 23:591-600

7. Leung TF, Ng PC, Tam WH, Li CY, Wong E, Ma TP, Lam CW, Fok TF 2004 Helper T-lymphocyte-related chemokines in healthy newborns. Pediatr Res 55:334338

8. Zhu J, Paul WE 2010 Heterogeneity and plasticity of T helper cells. Cell Res 20:4-12

9. Warner JA, Jones CA, Jones AC, Warner JO 2000 Prenatal origins of allergic disease. J Allergy Clin Immunol 105:S493-S498

10. Piccinni MP, Beloni L, Livi C, Maggi E, Scarselli G, Romagnani S 1998 Defective production of both leukemia inhibitory factor and type 2 T-helper cytokines by decidual $\mathrm{T}$ cells in unexplained recurrent abortions. Nat Med 4:1020-1024

11. Jenmalm MC, Björkstén B 1998 Development of the immune system in atopic children. Pediatr Allergy Immunol 9:5-12

12. Furuhjelm C, Warstedt K, Larsson J, Fredriksson M, Böttcher MF, Fälth-Magnusson K, Duchén K 2009 Fish oil supplementation in pregnancy and lactation may decrease the risk of infant allergy. Acta Paediatr 98:1461-1467

13. Warstedt K, Furuhjelm C, Duchén K, Fälth-Magnusson K, Fagerås M 2009 The effects of omega-3 fatty acid supplementation in pregnancy on maternal eicosanoid, cytokine, and chemokine secretion. Pediatr Res 66:212-217

14. Calder PC, Miles EA 2000 Fatty acids and atopic disease. Pediatr Allergy Immunol 11:29-36

15. Ma DW, Seo J, Switzer KC, Fan YY, McMurray DN, Lupton JR, Chapkin RS 2004 n-3 PUFA and membrane microdomains: a new frontier in bioactive lipid research. J Nutr Biochem 15:700-706

16. Spite M, Norling LV, Summers L, Yang R, Cooper D, Petasis NA, Flower RJ, Perretti M, Serhan CN 2009 Resolvin D2 is a potent regulator of leukocytes and controls microbial sepsis. Nature 461:1287-1291

17. Serhan CN 2005 Novel eicosanoid and docosanoid mediators: resolvins, docosatrienes, and neuroprotectins. Curr Opin Clin Nutr Metab Care 8:115-121

18. Gottrand F 2008 Long-chain polyunsaturated fatty acids influence the immune system of infants. J Nutr 138:1807S-1812S

19. Sweeney B, Puri P, Reen DJ 2001 Polyunsaturated fatty acids influence neonatal monocyte survival. Pediatr Surg Int 17:254-258

20. Sampath H, Ntambi JM 2005 Polyunsaturated fatty acid regulation of genes of lipid metabolism. Annu Rev Nutr 25:317-340

21. Lauritzen L, Kjaer TM, Fruekilde MB, Michaelsen KF, Frokiaer H 2005 Fish oil supplementation of lactating mothers affects cytokine production in $21 / 2$-year-old children. Lipids 40:669-676

22. Koletzko B, Demmelmair H, Schaeffer L, Illig T, Heinrich J 2008 Genetically determined variation in polyunsaturated fatty acid metabolism may result in different dietary requirements. Nestle Nutr Workshop Ser Pediatr Program 62:35-44; discussion 44-39

23. Holt PG, Rudin A, Macaubas C, Holt BJ, Rowe J, Loh R, Sly PD 2000 Development of immunologic memory against tetanus toxoid and pertactin antigens from the diphtheria-tetanus-pertussis vaccine in atopic versus nonatopic children. J Allergy Clin Immunol 105:1117-1122

24. Seymour JL, Keswick BH, Hanifin JM, Jordan WP, Milligan MC 1987 Clinical effects of diaper types on the skin of normal infants and infants with atopic dermatitis. J Am Acad Dermatol 17:988-997

25. Kaluzny MA, Duncan LA, Merritt MV, Epps DE 1985 Rapid separation of lipid classes in high yield and purity using bonded phase columns. J Lipid Res 26:135140

26. Dunstan JA, Mori TA, Barden A, Beilin LJ, Taylor AL, Holt PG, Prescott SL 2003 Fish oil supplementation in pregnancy modifies neonatal allergen-specific immune responses and clinical outcomes in infants at high risk of atopy: a randomized, controlled trial. J Allergy Clin Immunol 112:1178-1184

27. Dunstan JA, Mori TA, Barden A, Beilin LJ, Taylor AL, Holt PG, Prescott SL 2003 Maternal fish oil supplementation in pregnancy reduces interleukin-13 levels in cord blood of infants at high risk of atopy. Clin Exp Allergy 33:442-448

28. Virella G, Fourspring K, Hyman B, Haskill-Stroud R, Long L, Virella I, La Via M, Gross AJ, Lopes-Virella M 1991 Immunosuppressive effects of fish oil in normal human volunteers: correlation with the in vitro effects of eicosapentanoic acid on human lymphocytes. Clin Immunol Immunopathol 61:161-176

29. Prescott SL, Sly PD, Holt PG 1998 Raised serum IgE associated with reduced responsiveness to DPT vaccination during infancy. Lancet 351:1489

30. Yu G, Björkstén B 1998 Serum levels of phospholipid fatty acids in mothers and their babies in relation to allergic disease. Eur J Pediatr 157:298-303

31. Duchén K, Casas R, Fagerås-Böttcher M, Yu G, Björkstén B 2000 Human milk polyunsaturated long-chain fatty acids and secretory immunoglobulin A antibodies and early childhood allergy. Pediatr Allergy Immunol 11:29-39

32. Stafford AN, Rider SH, Hopkin JM, Cookson WO, Monaco AP 1994 A 2.8 Mb YAC contig in 11q12-q13 localizes candidate genes for atopy: Fc epsilon RI beta and CD20. Hum Mol Genet 3:779-785

33. Schaeffer L, Gohlke H, Muller M, Heid IM, Palmer LJ, Kompauer I, Demmelmair H, Illig T, Koletzko B, Heinrich J 2006 Common genetic variants of the FADS1 FADS2 gene cluster and their reconstructed haplotypes are associated with the fatty acid composition in phospholipids. Hum Mol Genet 15:1745-1756

34. Xie L, Innis SM 2008 Genetic variants of the FADS1 FADS2 gene cluster are associated with altered (n-6) and (n-3) essential fatty acids in plasma and erythrocyte phospholipids in women during pregnancy and in breast milk during lactation. J Nutr 138:2222-2228 